\title{
PALAVRAS ANTERIORES. OS PRÉ-DISCURSOS ENTRE MEMÓRIA E COGNIÇÃO
}

Há sempre um tio da América, um irmão mal-sucedido, uma tia que fugiu com um militar, um primo desempregado ou falido, um avô anarquista, uma avó no hospital, louca ou caduca.

G.Deleuze e F.Guattari, O Anti-Édipo

RESUMO: Ao se levar em consideração os quadros prévios da produção discursiva, é bem provável que se consiga enriquecer as teorias e os métodos da análise do discurso, ampliando o contexto que passa a abranger os dados ambientais e cognitivos do sujeito. Propomos recorrer à noção de pré-discurso ou de quadros pré-discursivos coletivos, que supõe uma redistribuição do coletivo e do individual (a noção do indivíduo coletivo) e a tomada em consideração, no quadro da cognição social, das ferramentas e artefatos na produção da fala (tecnologia discursiva).

PALAVRAS-CHAVE: Pré-discurso ou quadros pré-discursivos coletivos; memória; cognição social; tecnologia discursiva.

\section{INTRODUÇÃO}

epígrafe de Deleuze e Guattari não é apenas decorativa; no texto de $O$ anti-Édipo, ela é a resposta a uma questão anterior: "Mas de onde vêm os cortes e sua distribuição, que impedem precisamente a família de ser um interior?" (1972, p.116). Encontramos, nessa resposta, representações coleti-

Universidade de Paris 13, França. Tradução de Norma Seltzer Goldstein. 
vas, estereótipos psicológicos e comportamentais; e encontramos, sobretudo, a articulação da estrutura familiar com um exterior que é claramente definido como história. Isso corresponde à maneira como entendo o discurso, articulado com dados exteriores, históricos, culturais, sociais, ambientais, que o impedem de ser um simples interior fechado em si mesmo: é um discurso orientado por seus anteriores (memória dos pré-discursos) e configurado pelos quadros da percepção e da categorização de um mundo "tanto feito quanto encontrado" (expressão de Goodman que traduzo em termos cognitivos).

Na minha perspectiva, realmente, o discurso da análise do discurso ${ }^{1}$ não se reduz aos parâmetros enunciativos nem à situação de comunicação, nem tampouco à posição do sujeito (sociopragmático), mas deve levar em conta os dados sócio-históricos (o que se chamava na tradição da escola dita francesa representada por Pêcheux as "condições de produção") e ambientais. Falo de dados ambientais para designar, na perspectiva da cognição social, não só as relações entre os humanos e seus quadros de saberes, crenças e práticas (os pré-discursos, de que voltarei a falar), mas também as relações entre eles e sua ambientação material concreta (ambientes naturais ou artificiais, espaços, objetos, artefatos, suportes). Isso implica um remanejamento da noção de contexto, e, nesse caso, o termo "ambiente" me parece mais pertinente.

Essa formulação aparentemente pleonástica poderia significar: de um lado, que o discurso é objeto de múltiplas abordagens nas ciências da linguagem e nas ciências da informação e da comunicação, das mais estritamente linguiísticas (o discurso da semântica teórica do discurso, por exemplo) até as mais amplamente sociológicas (o discurso da análise de conteúdo), abordagens percorridas em Maingueneau (dir. 2005); por outro lado, que o sintagma análise do discurso corresponde, na nossa perspectiva, a uma abordagem científica localizável na história das ciências da linguagem, com seus fundadores (anos 60, Harris, Dubois, Pêcheux), seus conceitos teóricos (formação discursiva, inter e intradiscurso, pré-constructo, fio do discurso; vide Paveau, Rosier, 2005; Paveau, 2006a), suas evoluções e transformações (vide Guilhaumou, 2006). 
Sabe-se que dois paradigmas se desenham atualmente nas ciências cognitivas: o paradigma clássico e dominante das representações internas (os quadros mentais ou módulos neuronais de conhecimento estão dentro da cabeça, segundo as duas grandes correntes internalistas, uma gramatical, formal, vinda de Chomsky, e a outra semântica, representada por Lakoff, por exemplo) e outro, mais heterodoxo e mais recente, o da cognição social, correspondente a um paradigma sociocultural surgido nos anos 1990 nos Estados Unidos. Nessa ótica, o homem constrói quadros cognitivos na sua interação com o ambiente exterior, material, sendo que os agentes psíquicos não são apenas internos, mas também externos e, por vezes, não humanos: uma caderneta, um mapa, uma lista. Também uma árvore ou um prédio podem constituir agentes psíquicos que contribuem para a elaboração cognitiva. ${ }^{2} \mathrm{Na}$ minha opinião, a análise do discurso pode obter benefícios importantes dos aportes da cognição social e encontrar nessa corrente algumas condições de sua renovação e de um certo afunilamento teórico.

Após ter descrito os pré-discursos e seu funcionamento na construção das produções verbais, detalharei a noção de linhagem discursiva, proposta para dar conta dos fenômenos de filiação que lastram o sujeito com essas falas anteriores através das quais ele se faz entender. Escolherei em seguida um exemplo de "lugar de memória" discursiva, o nome próprio em contexto literário e histórico, e um exemplo de "des-memória" discursiva, sob a forma de um amálgama que constitui uma espécie de rombo na linhagem dos sentidos.

2 Para ser (realmente muito) breve, menciono aqui Suchman, aluno de Garfinkel, pioneiro da cognição situada nas atividades de linguagem; Lave, no mesmo paradigma, porém mais voltado para a prática; Cole e o Laboratory of human Cognition, fundado nos fins dos anos 1960, de onde saem os estudos pioneiros de Hutchins sobre a cognição distribuída (importância dos contextos materiais no funcionamento cognitivo); na França, é preciso citar principalmente Quéré. Conein, Thévenot para a introdução dessas correntes e os primeiros trabalhos na área; Latour e a sociologia associacionista; Lahou do lado da ergonomia e da cognição para o trabalho. 


\section{O APELO AOS PRÉ-DISCURSOS}

Propus a noção de pré-discurso (Paveau, 2006a) para responder às questões de determinações pré-linguiísticas da transposição em palavras. Entendo "determinações pré-linguiísticas" no sentido de dados anteriores à transposição em linguagem, de ordem perceptiva e representacional, mas pré-configuradas pela dimensão linguiística, nas quais se apóiam os mecanismos de produção linguageira. Como trabalho com o discurso, prefiro falar em pré-discurso e quadros pré-discursivos. E como a pesquisa nunca é suficientemente cumulativa, apesar de todo o cuidado e da paixão com que lemos nossos "antigos", só percebi mais tarde que o termo pré-discurso já figurava em Lacan (uma ocorrência no Seminário VI de 1958 para designar o sujeito antes da aquisição da fala); em Foucault, designando algo como um referente pré-determinado que o discurso só iria nomear posteriormente, idéia que o filósofo rejeita categoricamente na Arqueologia do saber, em 1969, e na Ordem do discurso, em 1971; bem como em Pêcheux, com o mesmo sentido, na Análise automática do discurso, em 1969. Mas é, sobretudo, o pré-constructo que está na origem da minha reflexão e todas as formas desses discursos ou representações "de antes", isto é, antes da transposição em discurso que impregnam explícita ou implicitamente todas as nossas produções verbais: verdadeira floresta terminológica em que se misturam saberes compartilhados, conhecimentos enciclopédicos, postulados silenciosos, estereótipos, quadros, scripts, frames etc. (Para uma descrição detalhada dessas noções, vide Paveau, 2006a).

\subsection{História do pré-constructo ou "De Pêcheux a Culioli"}

Optei por traçar aqui a história de um conceito fundamental em análise do discurso, amplamente difundido na pesquisa e inevitavelmente ampliado e enfraquecido. A idéia de um "discursivo prévio” aparece em Pêcheux já em 1966, data em que começa sua tese, 
Filol. lingüíst. port., n. 9, p. 311-331, 2007.

defendida em 1968 e publicada em 1969 com o título Análise automática do discurso:

Em outros termos, o processo discursivo não tem, por direito, um início: o discurso se escora sempre no discursivo prévio, que representa o papel de matéria prima, e o orador sabe que, quando evoca tal acontecimento que já foi objeto de um discurso, está ressucitando no espírito de seus ouvintes o discurso no qual esse acontecimento ocorreu . [...] (Pêcheux, 1969, p. 14-5; seção 2 do cap. II: "As implicações do conceito saussuriano de instituição")

A idéia dessa "matéria-prima" do discurso aparece numa passagem sobre a concepção da instituição em Saussure, que Pêcheux retoma acrescentando o que lhe parece estar faltando em Saussure, ou seja, a concepção sociológica das instituições tirada do Tratado de sociologia dirigido por G. Gurvitch em 1958. O discursivo prévio tem, portanto, de início, uma natureza profundamente social. Mas a noção de pré-constructo vai se forjar no plano linguíístico a partir da reflexão de Culioli, que postula a existência de um nível "prélexical" (nível do sentido potencial, antes de sua transposição em léxico), a partir do qual interviria uma "modulação retórica":

É possível [...] propor, apoiando a tese em argumentos teóricos, que existe num nível muito profundo (provavelmente pré-lexical), uma gramática das relações primitivas, onde a distinção entre sintaxe e semântica não faz nenhum sentido. Teremos, em seguida, um filtro lexical, com um certo número de regras sintáticas e semânticas, incluindo a modulação retórica (metáforas, desvios de sentido), que não poderia ser trazida para a sintaxe. (Culioli, Fuchs, Pêcheux, 1970, p. 7)

Em uma nota que aparece depois da palavra sintaxe, provavelmente da autoria de Pêcheux (conversa com Culioli, junho de 2006, vide Paveau, Rosier, no prelo), aparece, pela primeira vez, ao que nos consta, o termo interdiscurso, que constitui com o intradiscurso e o pré-constructo o sistema conceitual que engloba as três noções e fora do qual não se pode pensar nenhuma delas, separadamente:

Na sua definição clássica, a retórica diz respeito ao mesmo tempo ao que se poderia chamar de semântica das áreas [...] e "a ordem e o encadeamento das idéias" [...]. O uso da palavra retórica remete aqui explicita- 
PAVEAU, Marie-Anne. Palavras anteriores. Os pré-discursos entre memória e cognição

mente ao primeiro sentido [...]; deve-se observar, entretanto, que esse emprego remete implicitamente à existência do interdiscurso (efeito de um discurso sobre um outro discurso) como base sobre a qual se organizam os "mecanismos estratégicos" evocados acima. Isso significa que estamos no nível do "fala-se" ou do "isso fala por si mesmo", isto é, no nível não consciente (nível do pré-assertado: lexis e relação primitiva).

(Culioli, Fuchs, Pêcheux, 1970, p. 7; nota VII)

Lembremos que na reflexão feita em conjunto por Culioli e Pêcheux existem três níveis: o inassertado (nível em que as origens do discurso, o que Pêcheux chama de "discursos transversos", foram esquecidas), o pré-assertado (nível pré-lexical da lexis em potencialidade) e o assertado (nível da ocorrência, isto é, da relação de uma lexis com uma situação). O pré-constructo diz respeito ao inassertado, na medida em que corresponde a uma sequiência encaixada em uma outra de modo invisível, com um efeito de evidência prévia. $O$ encaixamento do pré-constructo é definido, assim, num texto de Fuchs e Pêcheux:

O encaixamento de um pré-constructo. Descrito na sua forma geral, esse mecanismo consiste em que uma sequiência $S^{3} \partial$ (por exemplo "o carteiro passa") encontra-se intercalada numa sequiência SÇ (por exemplo "a passagem do carteiro sempre diverte as crianças"). Ou ainda (exemplo tomado de P. Henry: "os números inteiros são densos"). Vê-se que é próprio desse primeiro mecanismo supor que o conteúdo da sequiência $S^{3}$ já estivesse ali, já fosse conhecido, disponível, no momento em que se enuncia SÇ. (Fuchs, Pêcheux, s.l.n.d, ca 1971, p. 33; tipografia dos autores)

Eles concluem, mais adiante, haver uma relação de anterioridade do inassertado sobre o assertado, o que será a base da teoria do pré-constructo, articulado com o inter e o intradiscurso, teoria elaborada para dar conta do funcionamento do discurso ideológico: "[...] o inassertado precede e governa o assertado e seus mecanismos".

Isso parece explicar que o efeito-sujeito possa ser descartado no funcionamento nocional-ideológico, sob as formas comentadas acima do encaixamento do pré-constructo por um lado, e do esquecimento do discurso transverso orientando uma substituição, por outro lado, ambas as formas pondo necessariamente em cena o "sujeito universal", que fun- 
Filol. lingüíst. port., n. 9, p. 311-331, 2007.

ciona como se não estivesse em lugar algum. [...] em termos lingüísticos, diríamos que o inassertado domina a asserção, e não o inverso. (Fuchs, Pêcheux, s.l.n.d., ca 1971, p. 41 e 46; tipografia dos autores)

A formulação mais conhecida segundo a qual "[...] o sujeito falante toma posição em relação a representações das quais ele é o suporte e que se encontram realizadas por pré-constructo lingüisticamente analisável" aparecerá na versão publicada desse trabalho (Pêcheux, Haroche e Henry, 1971, em Maldidier, 1990, p. 153), e, um pouco mais tarde, sob a pena de Henry, em 1975. Esse anterior do discurso, ligado ao inconsciente lacaniano (definido como o discurso do outro), está na verdade estreitamente conectado àquilo que eu chamo a memória do sentido, ainda que Pêcheux não raciocinasse, nessa época, em termos de memória (é a partir de 1980, da leitura de Foucault e dos trabalhos de Courtine, que a memória entrará no seu sistema de pensamento). Há no trabalho de Pêcheux e no da primeira geração dos analistas do discurso francês uma configuração conceptual em torno de determinações inconscientes do discurso, que se formulam nas noções de pré-constructo, de inassertado, de discursos transversos esquecidos.

Essa questão dos discursos anteriores se enfraqueceu um pouco nos trabalhos posteriores da análise do discurso, ou porque as noções de pré-constructo e de interdiscurso se simplificaram e congelaram, como mostram as entradas do Dicionário de análise do discurso (Charaudeau, Maingueneau, 2002), ou porque noções vindas de outras orientações constituíram respostas mais facilmente mobilizáveis, como a competência e suas declinações (linguiística, cultural, enciclopédica, interacional etc.), ou ainda porque certas etiquetas, como "saberes compartilhados", "estereótipos" ou "senso comum" têm contribuído para resolver o problema, nomeandoo . Mas em todos os casos, parece ter-se perdido o que fazia a riqueza e a exatidão da proposta de origem: o fato de que o pré-constructo, como aliás o interdiscurso, não depende da materialidade discursiva, e por isso não pode ser identificado como um conjunto de discursos concretamente proferidos, embora sendo lingüisticamente passíveis de análise. 


\subsection{Uma proposta sociocognitiva: os pré-discursos}

Os pré-discursos podem ser vistos como operadores na negociação do compartilhamento, da transmissão e da circulação do sentido nos grupos sociais: eu os defino como um conjunto de quadros pré-discursivos coletivos que têm um papel instrucional na produção e interpretação do sentido em discurso. São quadros de saber, de crença e de prática que não estão disponíveis apenas no espírito dos indivíduos e na cultura dos grupos (é sua natureza representacional), mas estão distribuídos, no sentido cognitivo desse termo, nos ambientes materiais da produção discursiva (sua natureza prática e mesmo técnica, como veremos). Os pré-discursos não são sequiências discursivas identificáveis (discursos que teriam sido produzidos antes, o que os aproximaria do discurso relatado e do dialogismo), mas quadros prévios tácitos, assinalados nos discursos atuais por um certo número de fenômenos. São dotados de seis características que os tornam analisáveis:

- sua coletividade, resultado de uma co-elaboração entre os indivíduos e entre o indivíduo e a sociedade;

- sua imaterialidade, já que a pré-discursividade é de ordem tácita (isto é, não formulável explicitamente, ao contrário do implícito);

- sua transmissibilidade, no eixo horizontal de comunicabilidade enciclopédica (a idéia do compartilhamento) e no eixo vertical da transmissão por meio das linhagens discursivas (o papel da memória);

- sua experiencialidade, já que permitem ao sujeito organizar e, também, antecipar seu comportamento discursivo;

- sua intersubjetividade, pois os critérios de mobilização são veri-relacionais, e não lógicos;

- sua discursividade, enfim, já que são linguageiramente assinalados. 
Filol. lingüíst. port., n. 9, p. 311-331, 2007.

\section{ROBINSON NA ARENA: INDIVÍDUO COLETIVO $\in$ TECNOLOGIA DISCURSIVA}

Escolhi examinar aqui, mais particularmente, dois desses traços, a coletividade e a transmissibilidade dos pré-discursos, antes de apresentar o exemplo dos nomes de memória nas linhagens discursivas.

\subsection{Os caminhos da coletividade e da transmissibilidade}

A coletividade dos pré-discursos coloca a questão da relação entre o individual e o coletivo. Parece-me que a eficácia dessa oposição binária tornou-se quase nula, nas ciências humanas e sociais, e que é mais rentável e sobretudo mais exato imaginar um continuum entre os dois. Se a psicologia social, ${ }^{3}$ a orientação marxista das ciências sociais ${ }^{4}$ e o conjunto dos trabalhos procedentes das versões sociais da linguiística (sociolinguiística, linguiística social e, numa certa medida, análise do discurso) enfatizaram legitimamente as determinações coletivas de nossos comportamentos nos últimos sessenta anos, foi preservada, entretanto, uma espécie de mito do indivíduo, o que Flahault chama de paradoxo de Robinson: mesmo Marx, explica ele, crê que o indivíduo precede a sociedade, feita para ele e em torno dele (Flahault, 2003). O que mostram ao mesmo tempo as neurociências cognitivas e as versões sociais e culturais da cognição (que não devemos, portanto, contradizer de modo muito radical), é que, apesar disso, o indivíduo cuja existência e manifestações não são contestadas, teria dificuldade em existir sem seus ambientes sociais, quaisquer que eles sejam.

3 Já nos anos 1920, Halbwachs, opondo-se à psicologia individualista dominante na época (Blondel), acentua a natureza coletiva dos fenômenos intuitivamente considerados os mais individuais: sonho, sentimentos diversos, maneiras de ser. Vide especialmente Halbwachs, 1938.

4 Bem representada na França pelos trabalhos de Bourdieu e de seus continuadores (Baudelot, Champagne, Sapiro, Passeron, Wacquant). 
Resumindo, Robinson estaria morto ou louco sem sexta-feira. Mas provavelmente porque esse deslocamento implica outros, e não menores (com isso deve-se repensar as oposições subjetivo vs objetivo, singular vs plural, interno vs externo), "o inconsciente cultural" francês ${ }^{5}$ e especialmente o da linguiística, tem dificuldade em se desfazer desses pré-discursos científicos da binaridade e da distribuição complementar. Entretanto, no meu entender, é preferível pensar as relações entre individual e coletivo de modo escalonar, embora se arriscando a esbarrar em dificuldades de análise e de interpretação, por falta de quadros de trabalho adequados, que devem então ser inventados.

Meu ponto de partida considera que existe uma co-elaboração ao mesmo tempo entre as produções discursivo-cognitivas individuais de cada um (meus quadros prévios e minha competência discursiva só podem ser ativadas em colaboração com as suas) e entre as produções individuais e sociais (meu comportamento individual está impregnado de social e, correlativamente, os fenômenos coletivos de uma sociedade estão marcados pelas inovações individuais). O problema é então identificar e descrever os pontos de passagem dos quadros pré-discursivos tanto entre os indivíduos, quanto entre o indivíduo e a sociedade, considerada aqui, é bom lembrar, um ambiente global. Nos trabalhos atuais dentro das disciplinas que trabalham com o discurso, circulam dois conceitos-etiquetas que propõem uma forma de solução a esse problema: o compartilhamento e a intersubjetividade. Digo "uma forma de solução", pois me parece que os procedimentos através dos quais são realizadas as articulações descritas acima não são, realmente, descritos e explicados.

\footnotetext{
"O sistema dos esquemas cognitivos que estão na base da construção da realidade e que são comuns ao conjunto de uma sociedade, num dado momento, constitui o inconsciente cultural, ou melhor, o transcendental histórico que fundamenta o sentido comum (ou a doxa), isto é, tudo o que é taken for granted, que é evidente, que nem precisa ser dito" (Bourdieu, 2000, p. 3).
} 
O compartilhamento aparece, por exemplo, sob a etiqueta de "saberes compartilhados" ou "conhecimentos compartilhados", etiqueta que se junta parcialmente à de implícito, como mostra a historiografia dessa noção estabelecida por Kerbrat $(1980,1986)$. Essa noção é também convocada em semântica no tratamento dos estereótipos (por exemplo, nos trabalhos de Kleiber sobre os estereótipos do tipo "comprei uma caneta e a pena está torta", "chegamos ao vilarejo e procuramos a igreja", nos quais a anáfora se justifica por "conhecimentos compartilhados"). Mas ficamos aí no nível de uma explicação, talvez de um slogan e o mecanismo do compartilhamento não é descrito.

A noção filosófica de intersubjetividade (inventada por Husserl nos anos 1910) tornou-se corrente em filosofia, a partir dos anos 1940, e é frequientemente mobilizada pelos lingüistas: Benveniste a usa já nos anos 1950, Culioli nos anos 1965-1975, antes de aparecer a noção de co-enunciação; Kleiber fala de "estabilidade intersubjetiva" nos anos 1990. O postulado da intersubjetividade é de fato necessário para dar conta de que pré-discursos, saberes, crenças e práticas anteriores coletivas de todos os locutores de um grupo ou de uma comunidade são mobilizados pelos locutores individuais que mantêm a ilusão, como teria dito Pêcheux, de construir versões individuais e originais do mundo. Mas tudo isso não nos diz como a coisa funciona efetivamente, como os pré-discursos se difundem entre os diversos agentes.

A mesma interrogação persiste no que se refere à sua transmissibilidade. Também por esse lado, uma abordagem cognitivodiscursiva implica alguns remanejamentos. A transmissão se faz em sincronia e em diacronia, se podemos dizer assim, pela circulação tácita entre os diversos agentes humanos e não humanos de uma sociedade e por filiação dos antepassados falantes a seus descendentes. A evocação de agentes não humanos talvez surpreenda, mas ela é coerente com meu desejo de propor uma versão ampla do contexto, integrando a dimensão prática, concreta e material de nosso ambiente: as técnicas, os objetos naturais, os artefatos, a 
decoração etc. O termo ambiente parece-me, aliás, mais pertinente que contexto. O paradigma da cognição social, versão distribuída, repousando justamente na idéia de uma co-construção dos conhecimentos por uma distribuição entre humanos e não humanos (o protótipo desse tipo de abordagem é o estudo de Hutchins sobre a construção da informação num cenário, vide Hutchins, 1994) parece-nos bastante mobilizável nesse empreendimento.

\subsection{A escolha da cognição social}

A cognição social é um conjunto muito vasto e variado (não se trata de modo algum de uma escola ou de uma doutrina única) de trabalhos que têm, em comum, o fato de contestar descle os anos 1990, em graus diversos, o princípio de base da cognição dita "clássica" (que se desenvolveu a partir dos anos 1950), isto é, a internalidade das funções cognitivas. Se o paradigma internalista se construiu em torno da inteligência artificial, da psicologia cognitiva, e depois da filosofia, da linguiística e das neurociências, o paradigma social e cultural ${ }^{6}$ vem sobretudo da sociologia, da antropologia e, em grau menor, da psicologia e da filosofia. Suchman defende, por exemplo, a tese segundo a qual a ação (na sua dimensão cognitiva) apela para outros recursos além das representações mentais (ou planos), isto é, para as características materiais, sociais e culturais de seu ambiente de ocorrência, que constituem a situação do agente ou dos agentes (1987). Situar-se nessa perspectiva significa, numa posição moderada, minorar o papel das representações mentais centrais, tanto entre os cognitivistas "ortodoxos" quanto na semântica cognitiva da costa oeste, e estabelecer a hipótese de uma elaboração cognitiva exterior ao espírito. Trata-se, portanto, de integrar as determinações sócio-históricas, como precisa Achard-Bayle:

6 Esclareço que social e cultural não se opõe aqui a individual, mas a interno. 
Filol. lingüíst. port., n. 9, p. 311-331, 2007.

As operações cognitivas da semântica californiana (esquematização, projeção, mistura, integração...) são encarnadas no sentido do "embodiment": quer se trate do movimento abstrato $(1987)^{7}$ de Langacker, das metáforas na vida cotidiana de Lakoff \& Johnson (1980/1985) ou das relações vitais (identidade, tempo, mudança...) de Fauconnier et Turner. (Turner, 2000; Fauconnier \& Turner, 2002/2003; Fauconnier, 2003).

Essas operações são, entretanto, "desencarnadas", no sentido social e histórico do termo. A dimensão sócio-histórica, dita também profundamente contextual, que supõe/suporta o trabalho interpretativo dos interlocutores, é a parente pobre das análises cognitivas ligadas ao funcionamento cerebral... (Achard-Bayle 2006, p. 11$){ }^{8}$

E isso significa, igualmente, aceitar a hipótese muito anticartesiana (mas conhecemos desde Damasio o erro de Descartes) e aparentemente contra-intuitiva, pelo menos para as formações acadêmicas francesas, no que se refere à exterioridade do espírito e da memória:

Nessa perspectiva, o espírito é inicialmente um "espírito objetivo", encarnado nas instituições, nas práticas estabelecidas, nas leis, nos usos e costumes de uma sociedade. A capacidade de pensar ou de adquirir conhecimentos é então menos uma capacidade de formar e de manipular representações internas do que uma capacidade de se engajar em práticas sociais que são animadas e articuladas por idéias comuns, crenças legítimas e sistemas conceptuais impessoais. (Quéré, 1998, p. 161)

Essa hipótese é, entretanto, menos rara do que parece na França, já que é defendida por Auroux a propósito das "estruturas cognitivas externas", no quadro de uma reflexão sobre as tecnologias intelectuais e as tecnologias da língua:

A hipótese contrária (à cognição na cabeça) repousa sobre a existência de estruturas cognitivas externas ao indivíduo. Essas estruturas desen-

7 Cf. Rastier (2005): "A espacialização do espírito aparece então como o meio de lhe conferir uma objetividade externa, que faça dele o objeto de uma ciência positiva, embora cognitiva, e o mantenha afastado da experiência pessoal, ritmada pela consciência íntima do tempo".

8 Vide a bibliografia de Achard-Bayle para as referências. 
PAVEAU, Marie-Anne. Palavras anteriores. Os pré-discursos entre memória e cognição

volveram-se graças à tecnologia intelectual da escrita; elas dependem também de instrumentos externos (livros, bibliotecas, instrumentos de cálculo e de observação etc.), bem como de estruturas sociais de produção e de acúmulo de conhecimentos (enciclopédias, sociedades eruditas, redes culturais de produção e reprodução do saber). O processo cognitivo depende da estruturação social tanto quanto a produção das riquezas. (Auroux, 1998, p. 6).

Utilizarei no meu trabalho a expressão lexicalizada exterioridade do espírito, mas, fiel à minha reserva diante das oposições binárias, prefiro colocar uma continuidade entre representações internas e externas. De fato, os pré-discursos se situam, na minha opinião, tanto "na cabeça" quanto nos ambientes exteriores. Sem sucumbir ao demônio da analogia, que espreita todos aqueles que praticam a transdisciplinaridade, essa maneira de ver parece-me estar associada ao que Althusser chamava de "ideologias práticas" ou "normas práticas":

\footnotetext{
Diremos, portanto, considerando um só sujeito (tal indivíduo), que a existência das idéias de sua crença é material, no sentido de que suas idéias são seus atos materiais inseridos em práticas materiais, regulados por rituais materiais, eles próprios definidos pelo aparelho ideológico material do qual dependem as idéias desse sujeito. (Althusser, 1995 [1970]: itál. do autor)
}

"Atos materiais", "práticas materiais": temos aí uma formulação do ambiente material que eu gostaria de levar em conta na análise do discurso. A cognição social permite, de fato, repensar de modo refrescante a velha noção de contexto, ${ }^{9}$ agora multidisponível e utilizada para tudo o que parece situar-se em torno ou fora do discurso e ter uma ligação ou uma influência sobre ele. $E$, da mesma forma que se deve pensar, a partir de agora, a memória e a consciência como externos, talvez se possa (re)pensar o contexto como interno à consciência e à memória, ao menos numa articulação entre o interno e o externo, sempre sob a forma de um continuum.

A partir dessas posições relacionadas com a natureza da função cognitiva, com o lugar do espírito e com a natureza do contex-

9 Esquece-se frequientemente de que o contexto aparece em lingüística nos anos 1920, quase simultaneamente em Bakhtine, Sapir e Malinovski. 
to, proponho a existência de uma "tecnologia discursiva", isto é, de um conjunto de procedimentos ligados a práticas ao mesmo tempo intelectuais e materiais, que permitam a coletivização e a transmissão dos pré-discursos. Proponho detalhar aqui o exemplo das linhagens discursivas, no seio das quais viajam, no tempo e no espaço, nomes de memórias portadores de valores semânticos e memoriais.

\section{NOMES DE MEMÓRIA E LINHAGENS DISCURSIVAS}

\subsection{A historicidade dos pré-discursos: memória e distribuição}

Para forjar a noção de linhagens discursivas, inspirei-me nas "linhagens linguíísticas e semióticas" de Nyckees (2003). Considerava-se ou reconsiderava-se aí a historicidade dos discursos e das significações que parece ter sido esquecida, atualmente, na análise do discurso, exceto pelos historiadores do discurso, como observa Mazière (2005). Nyckees mobiliza a noção de linhagem linguística e semiótica para descrever a constituição histórica e coletiva do sentido, no quadro de sua "arqueologia semântica":

\footnotetext{
A primeira dessas abordagens diz respeito ao problema da constituição coletiva dos significados, isto é, de sua origem e de sua transformação na história de um grupo linguiístico; os usuários herdam de fato significados já constituídos ou, para dizer mais precisamente [...], os locutores entram num reino de significações já constituídas. Consequientemente, não se poderia explicar o fenômeno das significações, sem levar em conta sua história anterior e seu desenvolvimento dentro de uma "linhagem" linguística (ou, mais geralmente, semiótica), linhagem que remonta de uma certa maneira aos primórdios da humanidade, mas que não poderíamos evidentemente reconstituir na sua totalidade. (Nyckees, 2003, p. 65)
}

A idéia de um "reino de significações" prévias está particularmente de acordo com a noção de pré-discurso como quadros anteriores, transmitidos de discurso em discurso, através do tempo. Na minha perspectiva, é a memória que vai constituir o principal agente dessa transmissão, mas não uma memória reduzida à simples estocagem e desestocagem de informações semânticas e enciclopédicas. Trata-se, de fato, de uma memória cognitivo-discursiva, 
que elabora as linhagens discursivas, as quais podem ser definidas como dispositivos representacionais internos e externos, permitindo acolher e transmitir conteúdos semânticos ligados aos saberes, crenças e práticas. Isso quer dizer que existem "lugares de memória" discursivos e cognitivos. Entre eles, citarei, por exemplo, os lugares de memória da língua, como o etimologismo, que constitui uma linhagem discursiva exata ou fantasmática, ${ }^{10}$ dentro da qual se transmite o sentido das palavras. Trata-se de um dispositivo ao mesmo tempo interno, já que o saber etimológico é um saber intelectual (é inclusive um dos protótipos do saber erudito e mundano na França), e externo, pois está inserido num certo número de ferramentas linguísticas como os dicionários, manuais e tratados que dizem respeito à língua, bem como nos recursos eletrônicos que permitem atualmente outras formas de circulação do saber. $\mathrm{O}$ conjunto desses recursos materiais constitui uma memória externa e diremos, então, que o pré-discurso etimológico está distribuído entre agentes psíquicos humanos e não humanos (os artefatos). ${ }^{11}$

Examinarei agora uma forma de linhagem discursiva particularmente eficaz na transmissão dos pré-discursos, que chamamos de nome de memória.

\subsection{Nomes próprios: paradigma demoníaco}

Parto de uma concepção do nome próprio como "designador brando", termo que adotei para descrevê-lo como portador de sentido e de valores identitários, culturais e ideológicos instáveis e relativos (Paveau, 2006b, 2007 no prelo). Sem fazer uma revisão histórica das teorias que dão um espaço para o sentido do nome próprio, lembrarei simplesmente que esse paradigma foi introduzi-

10 Faço aqui alusão aos usos argumentativos do argumentum ab etymologia, às vezes fantasiosos, mas sempre persuasivos, como já assinala Paulhan no seu pequeno tratado de 1953: A prova pela etimologia.

11 Para detalhes sobre as diversas manifestações das linhagens discursivas, vide Paveau, 2006a. 
do nas ciências da linguagem, na França, pelos trabalhos de Siblot (1987), a partir, entre outras, das posições da antropologia (LéviStrauss, Isaacs, Molino, Zonabend), cujos ecos se encontram na literatura (basta lembrar a extraordinária teoria profana de Proust na obra Em busca do tempo perdido), mas também nos discursos mundanos que esboçam algo como "o espírito francês" (Daninos, Schifres). Apóio, portanto, inteiramente, as abordagens que se multiplicam atualmente em torno da polissemia, ou plurivocidade, ou "hibridação" (Cislaru), ou ainda "polivalência intrínseca" (Lecolle) do nome próprio. Elas supõem particularmente a sua heteroreferencialidade, isto é, a sua capacidade de indicar vários referentes ao mesmo tempo, sem que se possa identificá-los sempre e atribuir-lhes uma ordem de prioridade. Assim, um topônimo (por exemplo, o Líbano) será também praxônimo (nome próprio de evento, vide sobre essa questão Cislaru, 2005), e um antropônimo será carregado de valores sociais (na França, é melhor chamar-se Montmorency que Labite, Paul que Marcel, Léa que Georgette etc.). Tratei em outra publicação da questão da superposição de sentidos do topônimo (Paveau, 2006a) e do polemônimo (Bir-Hakein e Gravelotte em Paveau, 2006b, Diên Biên Phu, em Paveau, 2007 no prelo). Menciono aqui o corpus específico dos nomes do diabo, proposto por Certeau em A escrita da história. Voltando à questão das possuídas de Loudun, que é objeto de uma de suas obras anteriores (1970, A possessão de Loudun, Paris, Gallimard), Certeau dedica uma seção ao nome próprio em $A$ escrita da história, intitulada "O quadro dos nomes próprios: uma toponímia em movimento (1975, p. 306). O nome próprio diabólico possui nesse contexto um valor de reconhecimento daquilo que faz irrupção no grupo, ao mesmo tempo em que tem uma função social importante, já que, nomeando o poder diabólico, serve para produzir um discurso social sobre a possessão. Certeau explica que esse tipo de denominação "funciona ao mesmo tempo como participação em um sistema e como acesso ao simbólico" (1975, p. 309; itál. do autor). Mas em Loudun, "assistimos [...], por um enfraquecimento das figuras , por uma espécie de fusão de imagens, à mutação de Léviathan em outra coisa 
que se chama Aman ou então à irrupção de um Souvillon (uma espécie de piada erótica) ou de uma Queue de chien entre Isacaron e Béhémot" (1975, p. 307). O paradigma demonológico habitual é de fato modificado pela "infiltração de instâncias outras que as demonológicas" (1975, p. 310; itál. do autor), que saem do quadro religioso. Os 55 nomes que podemos identificar nas confissões dividem-se da seguinte maneira:

- "Nomes patenteados e garantidos pela literatura demonológica”: Asmodée, Astaroth, Balam, Béhémoth, Belzébuth, Berith, Isacaron etc.

- Outros "nomes hebreus, tirados de uma tradição mais esotérica": Achaph, Agal, Aman (variante de Amon ?), Barberith (composto de Berith), Caleph, Caph, Eazar(ou Eazas) Lezearetc.

- Significantes da mitologia greco-latina : Caron, Cerbère, Castori etc.

- Nomenclatura heresiológica cristã: Celse, Lucien, Luther etc.

- Nomes comuns transformando-se em nomes próprios: Fósforo de impureza, Carvão de impureza, Concupiscência, Inimigo da Virgem, Fornicação, Leão do Inferno, Rabo de cachorro, Poluição etc.

- Tradições populares, localizações provinciais ou fundo regional: Buffetison, Carreau, Cédon, Elimy, Grelet ou Grelier, Legret, Luret, Luvret, Maron, Penault, Pérou, Rebat, Souvillon etc. $(1975$, p. $310-1)$.

Compreende-se que a hipótese do nome próprio como "designador brando" é aqui uma necessidade interpretativa: esses nomes estão ligados, por um lado, a um "dicionário nobre e oficial", o da demonologia e da cultura greco-latina, mais frequientemente associado a religiosas aristocratas que ocupam altos cargos, e por outro lado, a um reservatório mais popular associado a irmãs 
mais modestas no plano social, mas igualmente hierárquico. Certeau observa que esses nomes esboçam, além ou através da ordem demoníaca, uma ordem política. São a heteroreferencialidade e os valores associados a esses nomes que permitem, a partir dos prédiscursos carreados por eles, que se elabore um outro espaço do discurso demonológico, que seja iniciada a bela coerência do sistema religioso que atribui aos possuídos lugares e nomes fixos. Certeau vê aí a passagem de uma "epistemologia da transparência", reino das relações ontológicas entre o nome e a coisa, a uma "epistemologia de superfície", constituída de relações entre significantes. Passa-se da existência da verdade à manifestação de um olhar e essa passagem coloca para Certeau a questão do sujeito "na linguagem da ilusão" (1975, p. 315). Compreende-se, portanto, que os nomes de memória constituam dispositivos discursivos cognitivos que organizam, nesse exemplo, a passagem de uma ordem de conhecimento e de realidade para uma outra.

\section{CONCLUSÃO}

A análise do discurso francesa dos anos 1960 e 1970 propunha a tomada em consideração das "condições sócio-históricas de produção" do discurso. Uma vez que a evolução dessa disciplina seria inseparável da do conjunto das ciências, temos de enfatizar a necessidade de repensar essa versão do contexto, à luz dos avanços das ciências cognitivas, um dos paradigmas mais extensos e prolíficos dos últimos sessenta anos. A cognição nos apresenta nosso ambiente sob um novo dia e permite à análise do discurso, lastrando-se da questão da memória e da de distribuição, propor uma nova articulação entre o discurso e seus exteriores. 
PAVEAU, Marie-Anne. Palavras anteriores. Os pré-discursos entre memória e cognição

\section{BIBLIOGRAFIA}

ACHARD-BAYLE, G. (2006) Les sémantiques cognitives et la question de l'objectivisme. Communicação no colóquio Rencontres de Sémantique et de Pragmatique 4, Orléans, junho (documento de trabalho).

ALTHUSSER, L. (1995 [1970]) Idéologie et appareils idéologiques d’État. In: Sur la reproduction. Paris: Presses Universitaires de France, Actuel Marx Confrontations, p. 269314.

AUROUX, S. (1998) La raison, le langage et les normes. Paris: Presses Universitaires de France, coll. "Sciences, modernités, philosophies".

BOURDIEU, P. (2000) Linconscient d'école. In: Actes de la recherche en sciences sociales, 135. Paris: Seuil, p. 3-5.

CERTEAU, M. (de) (1975) L'écriture de l'histoire. Paris: Gallimard.

CISLARU, G. (2005) Étude sémantique et discursive du nom de pays dans la presse française. Tese (Doutorado) - Université de Paris3-Sorbonne nouvelle.

CULIOLI, A., FUCHS C., PÊCHEUX M. (1970) Considérations théoriques à propos du traitement formel du langage. Paris: Dunod, Documents de linguistique quantitative, 7.

DELEUZE, M.; GUATTARI, F. (1972) L'anti-CEdipe. Paris: Minuit.

FLAHAULT, F. (2005) Le paradoxe de Robinson. Capitalisme et société, Paris: Mille et Une Nuits.

FOUCAULT, M. (1971) L'ordre du discours. Paris: Gallimard. . (1969) L'archéologie du savoir. Paris: Gallimard.

FUCHS C.; PÊCHEUX M., s.d. (ca 1971) La détermination: relatives et déterminants. Monografia s.l.n.d., 46 p. datilografadas (incompleto, 2 primeiros capítulos).

GOODMAN, N. (1992/1978) Manières de faire des mondes. Trad. M.-D. Popelard. Paris: Jacqueline Chambon.

GUILHAUMOU, J. (2006) Discours et événement. L'histoire langagière des concepts. Besançon: Presses Universitaires de Franche-Comté.

HUTCHINS, E., (1994 [1991]) Comment le cockpit se souvient de ses vitesses. Trad. de How a Cockpit Remembers its Speed. Sociologie du travail, 4, p. 461-73.

HALBWACHS, M. (1938) Esquisse d'une psychologie des classes sociales. Paris: Librairie Marcel Rivière et Cie, versão numérica por-M. Tremblay. Disponível em <http:/www.uqac.uquebec.ca/zone30/ Classiques_des_sciences_sociales/index.html >. Acesso em 29 ago. 2006.

KERBRAT-ORECCHIONI, C. (1986) Limplicite. Paris: A. Colin. . (1980) L'énonciation. De la subjectivité dans le langage. Paris: A. Colin.

LACAN, J. (1958-1959) Le désir et son interprétation, Séminaire VI, Sténotypie de l'École freudienne, fac-similé en ligne sur www.ecole-lacanienne.org. Acesso em 23 ago. 2005. LEROY S. (2004) Le nom propre en français. Paris: Ophrys.

MAINGUENEAU, D. (éd.). (2005) L’analyse du discours. État de l'art et perspectives. Marges linguistiques, 9, disponível em www.marges-linguistiques.com 
Filol. lingüíst. port., n. 9, p. 311-331, 2007.

MALDIDIER, D., (1990) (prés.) Linquiétude du discours. Textes de M. Pêcheux. Paris: Éditions des Cendres.

PAVEAU, M.-A. (2007) (no prelo) Le toponyme, désignateur souple et organisateur mémoriel. L'exemple du nom de bataille. Mots. Les langages du politique, 86, "Toponymes".

. (2006a) Les prédiscours. Sens, mémoire, cognition. Paris: Presses de la Sorbonne Nouvelle.

(2006b) De Gravelotte à Diên Biên Phu. Le feuilleté mémoriel des noms de bataille. Comunicação na jornada de estudo Le nom propre en discours. Université de Paris 3Sorbonne Nouvelle.

. (en cours) Pour une histoire des idées. Les analystes du discours 1968-2002. Pesquisa $\overline{\text { FNRS }}$ por entrevistas filmadas com cerca de quarenta analistas do discurso.

PAVEAU, M.-A.; ROSIER, L. (2005) Eléments pour une histoire de l'analyse du discours. Théories en conflit et ciment phraséologique. Comunicação no colóquio franco-alemão: L'analyse du discours en France et en Allemagne: Tendances actuelles en sciences du langage et sciences sociales . Université de Paris 12, Céditec, 2 Juillet. Disponível em <www.johannes angermueller.de/deutsch/ADFA/paveaurosier.pdf $>$.

PÊCHEUX, M. (1969) Analyse automatique du discours. Paris: Dunod.

PÊCHEUX, M.; HAROCHE, C.; HENRY, P., (1971) La sémantique et la coupure saussurienne. Langages, 24, "Épistémologie de la linguistique”, retomado em Maldidier, 1990, p. 133-53. QUÉRÉ, L. (1998) La cognition comme action incarnée. In: BORZEIX, A. et al. (dir.). Sociologie et connaissance. Nouvelles approches cognitives. Paris: CNRS Éditions, p. 143-64.

SIBLOT, P. (1987) De la signifiance du nom propre. Cahiers de praxématique, 8, p. 97-114. SUCHMAN, L. (1987) Plans and situated actions: the problem of human/machine communication. Cambridge: Cambridge University Press.

RÉSUMÉ: La pris en compte des cadres préalables de la production discursive peut sans doute enrichir les théories et méhodes de l'analyse du discours en élargissant le contexte aux données environnementales et cognitives du sujet. Nous proposons de recourir à la notion de prédiscours ou cadres prédiscursifs collectifs qui suppose une redistribution du collectif et de l'individuel (la notion d'individu collectif) et la prise en considération, dans le cadre de la cognition sociale, des outils et artefacts dans la production de la parole (technologie discursive)

MOTS-CLÉS: Prédiscours ou cadres prédiscursifs collectifs; mémoire; cognition sociale; technologie discursive. 